\title{
Brief Communication: \\ Scalar Structure of Turbulent Stratified Swirl Flames \\ Conditioned on Local Equivalence Ratio
}

\author{
M. Mustafa Kamal ${ }^{\mathrm{a}, \mathrm{c}, *}$, Robert S. Barlow ${ }^{\mathrm{b}}$, Simone Hochgreb $^{\mathrm{a}}$ \\ ${ }^{a}$ Department of Engineering, University of Cambridge, CB2 1PZ, Cambridge, United Kingdom \\ ${ }^{\mathrm{b}}$ Sandia National Laboratories, California, United States of America \\ ${ }^{\mathrm{c}}$ U.S.A.-Pakistan Centre of Advanced Studies in Energy (USPCAS-E), University of Engineering and \\ Technology Peshawar, Pakistan
}

\begin{abstract}
In a recent paper (Kamal, et al., 2015, Combustion and Flame, 162(10), 3896-3913), we reanalysed single shot species and temperature measurements from non-swirling flames stabilized on the Cambridge/Sandia stratified burner by conditioning measurements on the local equivalence ratio, and found that the state space structure of the flames was closely approximated by that of a laminar flame at the given equivalence ratio. In the present communication, we show that the same state space relationships remain robust for species $\mathrm{CH}_{4}, \mathrm{O}_{2}, \mathrm{H}_{2} \mathrm{O}$, and $\mathrm{CO}_{2}$ in premixed and stratified flames under high swirl. Conditioned mass fractions of $\mathrm{CO}$ and $\mathrm{H}_{2}$ in the stratified swirl flame show a greater effect of stratification than was observed in the non-swirling cases, and this is attributed to larger gradients in equivalence ratio that occur with the addition of swirl. Aside from this modest effect of stratification, major species mass fractions in the swirling flame are also closely approximated by laminar flame results at the local equivalence ratio.
\end{abstract}

Keywords: Turbulent stratified combustion, Swirling flames, Co-annular jet burner, Bluffbody stabilized flame, Highly swirling flows

\footnotetext{
${ }^{*}$ Corresponding author. Tel.: +44 1223764098

Email address: mmk44@cam.ac.uk
} 


\section{Introduction}

In a recent paper [1], the structure of premixed and stratified turbulent flames was analysed based on the species and temperature database generated from the Cambridge/Sandia burner [2] [3]. A major conclusion of [1] was that the relationship between major species mass fractions and temperature is primarily a function of the local equivalence ratio, with only secondary effects attributed to stratification and differential diffusion. The study also concluded that the mean scalar dissipation rate is lower than the nominal value for a laminar flame, owing to turbulent mixing.

The present study extends the conditional analysis to premixed and stratified flames in the same dataset, but which include swirl. These flames burn in the thin flame zone of the Borghi diagram (See Fig. 14 in [4]), where we expect that the reaction zone is not disrupted by turbulence, but the thermal zone is. Swirl leads to the following additional effects on the flames [4]: (a) higher levels of turbulence, with Karlovitz numbers up to 20 in the flame zone (as opposed to 6 in the non-swirling flames), and a ratio of turbulence intensity to laminar flame speed, $u^{\prime} / S_{L}$, up to 14 (compared to 7 in the non-swirling flame); (b) significant three-dimensional effects owing to the tangential component of velocity, and significant changes in flame shape and velocity profiles, with strong entrainment of air from outside into the product recirculation zone; and (c) larger gradients of equivalence ratio across the flame [2] [3]. In this short communication, the same analysis techniques used in [1] are applied to premixed and stratified swirl flames to determine how swirl affects the relationships between species and temperature.

\section{Experimental details}

\subsection{Burner and operating conditions}

The burner has been described in the previous studies [2] [3] [4] [5], and the reader is referred to the prior publications for details. The burner consists of two co-annular channels, with the flame stabilized by a central bluff body. Both inner and outer annuli are fed with specified premixed streams of methane and air. The main difference in the present study is that the outer annular flow is split between axial and tangential flow at the bottom of the mixture inlet, generating swirl and increased turbulence.

Only three flames are considered in this communication, but all of the swirl cases from [3] yielded results consistent with those presented here. Operating conditions are listed in Table 1. SwB1, which is uniformly premixed and without swirl, serves as a baseline. 
SwB3 adds strong swirl, and SwB11 combines strong swirl and high stratification. For all cases the bulk axial velocities in the inner and outer annuli were $U_{i}=8.3 \mathrm{~m} / \mathrm{s}$ and $U_{o}=$ $18.7 \mathrm{~m} / \mathrm{s}$, respectively, with laminar co-flow air at $U_{c o}=0.4 \mathrm{~m} / \mathrm{s}$. In the stratified swirl flame, SwB11, the turbulent flame brush crosses the centre of the mixing layer between inner and outer annular flows $(\phi \approx 0.75)$ at a distance $z=30 \mathrm{~mm}$ above the burner exit plane. Accordingly, we focus on results from this downstream location to compare scalar structure in the three flames.

\subsection{Diagnostics}

As described in [1] [2], experiments were conducted at Sandia National Laboratories. The diagnostic setup allows for the line measurement of temperature and major species $\left(\mathrm{CH}_{4}, \mathrm{CO}_{2}, \mathrm{CO}, \mathrm{H}_{2}, \mathrm{H}_{2} \mathrm{O}\right.$ and $\left.\mathrm{O}_{2}\right)$, with simultaneous cross-planar OH-LIF imaging to determine the instantaneous flame orientation relative to the measurement line. The species and temperature profiles were obtained by translating the $6.18 \mathrm{~mm}$ probe volume through each flame in overlapping steps, with 500 shots acquired at each step. The focus had a diameter of approximately $0.22 \mathrm{~mm}\left(1 / \mathrm{e}^{2}\right)$. The projected binned-pixel spacing for the combined Raman/Rayleigh/CO-LIF data was $103 \mu \mathrm{m}$. Measurement uncertainties are discussed in detail in [2], but are under $5 \%$ of the conditional mean for most species mass fractions, except $\mathrm{CO}$ and $\mathrm{H}_{2}(10 \%)$, and around $2 \%$ for temperature. Turbulent velocity measurements acquired with laser Doppler anemometry (LDA) and particle image velocimetry (PIV) by Zhou et al. [4] place the Kolmogorov length scale around $30 \mu \mathrm{m}$ in the middle of the shear layer between inner and outer annular flows (non-reacting) at a downstream distance of $z=30 \mathrm{~mm}$.

\section{Results}

\subsection{Conditioned species state space maps}

In the same way as was done for the non-swirling flames in [1], species mass fractions in the swirl flames were conditioned on the instantaneous local equivalence ratio. The equivalence ratio is reconstructed from the atomic balance of the measured species molar fractions, $X_{\mathrm{i}}$ :

$$
\phi=\frac{X_{\mathrm{CO}_{2}}+2 X_{\mathrm{CH}_{4}}+X_{C O}+0.5\left(X_{\mathrm{H}_{2} \mathrm{O}}+X_{\mathrm{H}_{2}}\right)}{X_{\mathrm{CO}_{2}}+X_{\mathrm{O}_{2}}+0.5\left(X_{C O}+X_{\mathrm{H}_{2} \mathrm{O}}\right)}
$$


Figure 1 shows $\mathrm{CH}_{4}, \mathrm{H}_{2} \mathrm{O}, \mathrm{O}_{2}, \mathrm{CO}_{2}, \mathrm{CO}$, and $\mathrm{H}_{2}$ mass fractions as functions of temperature for narrow ranges in equivalence ratio. Results of unstrained and strained laminar flame calculations at the corresponding equivalence ratio are included for comparison. The selected strain rate of $1000 \mathrm{~s}^{-1}$ is representative of the radial gradient in mean axial velocity across the shear layer at $z=30 \mathrm{~mm}$ above the burner exit in the swirling flames.

In the case of $\mathrm{CH}_{4}$, the good agreement shows that all swirling and non-swirling flames [1], fuel disappearance is only controlled by the local equivalence ratio and temperature according to the relationships in laminar flames, even at high equivalence ratios. The same is observed for $\mathrm{H}_{2} \mathrm{O}$ and $\mathrm{O}_{2}$. Note also that there is little effect of strain rate on the laminar results for mass fractions of $\mathrm{CH}_{4}, \mathrm{H}_{2} \mathrm{O}$ and $\mathrm{O}_{2}$. (See also Fig. 7 in [1].)

The conditional mean $\mathrm{CO}_{2}$ measurements for the zero swirl case $\mathrm{SwB} 1$ are between the strained and unstrained laminar curves, whereas the values for the swirling premixed (SwB3) and stratified cases (SwB11) (except those for $\phi=0.65)$, agree well with the strained laminar flame. The influence of higher strain is apparent in both swirling cases (SwB3 and SwB11), as expected from the calculated higher sensitivity of $\mathrm{CO}_{2}$ to strain, but there is no obvious additional influence of local gradients in equivalence ratio for the stratified case SwB11 compared to SwB3. Thus, as concluded in [1] for the non-swirl cases, Fig. 1 demonstrates that the state space behaviour of $\mathrm{CO}_{2}$ mass fraction in the stratified swirling flame is also primarily a function of local equivalence ratio.

In the case of $\mathrm{CO}$, the peak in the conditional mean for the non-swirling premixed flame SwB1 is consistent with the unstrained laminar calculation, while that in the swirling premixed flame SwB3 is consistent with the lower CO levels found in the $1000 \mathrm{~s}^{-1}$ strained calculation. The flame brush in SwB3 at $z=30 \mathrm{~mm}$ occupies a narrow region between the conical recirculation zone and the outer mixing layer between reactants and coflow air. Inclusion of slightly diluted samples from these regions within the conditioning interval in equivalence ratio could reduce the mean $\mathrm{CO}$ levels. However, narrowing the conditioning interval to $\phi=0.75 \pm 0.5 \%$ caused no change in the conditional mean. Therefore, the lower CO levels in SwB3 compared to SwB1 can be attributed to increased strain associated with the addition of swirl. The two swirling cases, SwB3 and SwB11, have comparable levels of bulk strain and turbulence intensity, but the peak $\mathrm{CO}$ level in the stratified case, conditioned on $\phi=0.75 \pm 2.5 \%$, is higher than in the premixed case. For each of the four conditioning intervals in local equivalence ratio, the peaks in measured $\mathrm{CO}$ in $\mathrm{SwB} 11$ are 
approximately equal to those in the corresponding unstrained laminar flame. This suggests that the effect of stratification on $\mathrm{CO}$ in SwB11 roughly offsets the effect of increased turbulence.

The effect of stratification on CO levels in the swirling flames (comparing SwB3 and SwB11 at the $\phi=0.75 \pm 2.5 \%$ condition) is greater than in the corresponding non-swirling flames (as shown in [1] by comparing SwB1 and SwB9 at the $\phi=0.75 \pm 2.5 \%$ condition). This can be attributed to the fact that the increased levels of turbulence generated by adding swirl also produce larger gradients in equivalence ratio across the flame. Distributions of the instantaneous change in equivalence ratio across the thermal ramp in all of the premixed and stratified, swirling and nonswirling flames were reported by Sweeney et al. [2,3], and the reported mean values at $z=30 \mathrm{~mm}$ are $\overline{\Delta \phi}=0.17$ in the non-swirling stratified flame, SwB9, and $\overline{\Delta \phi}=0.28$ in the swirling stratified flame, SwB11. It is important to note that peak heat release in lean premixed methane flames occurs near the location of peak $\mathrm{CO}$ mass fraction. While results in Fig. 1 reveal a modest elevation in peak CO levels due to stratification, the conditional mean $\mathrm{CO}$ levels are still primarily a function of local equivalence ratio.

For the highly stratified case SwB11, at temperatures below the point of peak CO, the measured mean values are somewhat higher than the laminar calculations. This can be seen by comparing the SwB11 mean results conditioned on $\phi=0.75$ with SwB1 and SwB3. This difference was also seen in [1] for the non-swirling stratified flames, and it may well be an effect of stratification, with elevated $\mathrm{CO}$ levels from the richer product zones diffusing toward the leaner preheat region of the flame.

Results for $\mathrm{H}_{2}$ follow trends similar to those for $\mathrm{CO} . \mathrm{H}_{2}$ levels are slightly lower in SwB3 than in SwB1, due to increased turbulence in the swirling premixed case, and they are higher in SwB11, conditioned on the corresponding equivalence ratio, than in SwB3, due to stratification. For each of the four conditioning intervals the elevation of $\mathrm{H}_{2}$ levels is greatest at low and intermediate temperature, rather than the region of maximum heat release. This is attributed to rapid diffusion of $\mathrm{H}_{2}$ from richer regions of the stratified flame. At higher temperatures and especially at higher local equivalence ratios, the effects of stratification on $\mathrm{H}_{2}$ are relatively minor compared to effect of local equivalence ratio in the premixed calculations. 


\section{Conclusions}

The experimental database of stable species and temperature obtained for the Cambridge/Sandia stratified burner has been reanalysed for cases with swirl, and the behaviour compared to the non-swirling cases [1] [2]. The species mass fractions were conditioned on the local equivalence ratio, and plotted as functions of the local temperature. These profiles were compared to unstrained and strained laminar profiles at the corresponding equivalence ratio.

The findings regarding the species state space are similar to the cases without swirl. When conditioned on equivalence ratio, the mass fractions of $\mathrm{CH}_{4}, \mathrm{O}_{2}, \mathrm{H}_{2} \mathrm{O}$, and $\mathrm{CO}_{2}$ agree well with laminar calculations at the corresponding equivalence ratio. Mass fractions of $\mathrm{CO}$ and $\mathrm{H}_{2}$ are high relative to the laminar flame results at temperatures corresponding to the preheat zone, and this is attributed to stratification. The effects of stratification on CO and $\mathrm{H}_{2}$ are somewhat greater in the swirling flame because the addition of swirl increases turbulence intensity and produces higher instantaneous gradients in equivalence ratio. However, the central conclusion from [1], that state-space relations in stratified flames are mainly a function of local equivalence ratio, can be extended to the swirling cases.

\section{Acknowledgements}

M. Mustafa Kamal acknowledges funding from University of Engineering and Technology Peshawar (Pakistan). The measurements at Sandia National Labs were sponsored by the United States Department of Energy, Office of Basic Energy Sciences, Division of Chemical Sciences, Geosciences and Biosciences. Sandia National Laboratories is a multiprogram laboratory operated by Sandia Corporation, a Lockheed Martin Company, for the United States Department of Energy under contract DE-AC04-94-AL85000. The exchange of researchers was made possible by an international networking grant of The Leverhulme Trust. 


\section{References}

[1] M. M. Kamal, R. S. Barlow, and S. Hochgreb, Conditional analysis of turbulent premixed and stratified flames on local equivalence ratio and progress of reaction, Combust. Flame 162 (2015) 3896-3913.

[2] M. S. Sweeney, S. Hochgreb, M. J. Dunn, and R. S. Barlow, The structure of turbulent stratified and premixed methane/ air flames I: Non-swirling flows, Combust. Flame 159 (2012) 2896-2911.

[3] M. S. Sweeney, S. Hochgreb, M. J. Dunn, and R. S. Barlow, The structure of turbulent stratified and premixed methane/ air flames II: Swirling flows, Combust. Flame 159 (2012) 2912-2929.

[4] R. Zhou, S. Balusamy, M. S. Sweeney, R. S. Barlow, and S. Hochgreb, Flow field measurements of a series of turbulent premixed and stratified methane/air flames, Combust. Flame 160 (2013) 2017-2028.

[5] M. M. Kamal, R. Zhou, S. Balusamy, and S. Hochgreb, Favre- and Reynolds-averaged velocity measurements: Interpreting PIV and LDA measurements in combustion, Proc. Combust. Inst. 35 (2015) 3803-3811. 


\section{Figure Captions}

Figure 1. Mass fractions of $\mathrm{CH}_{4}, \mathrm{H}_{2} \mathrm{O}, \mathrm{O}_{2}, \mathrm{CO}_{2}, \mathrm{CO}$, and $\mathrm{H}_{2}$ plotted as functions of temperature, conditioned on equivalence ratio and colored by the probability density, represented by the PDF, for cases $\mathrm{SwB} 1, \mathrm{SwB} 3$ and $\mathrm{SwB} 11$ at axial location $z=30 \mathrm{~mm}$. Mean values are plotted in blue, and vertical blue bars denote one standard deviation. Black solid lines represent the unstrained laminar calculations and black dotted lines represent strained $\left(1000 \mathrm{~s}^{-1}\right)$ laminar flame calculations, at the midpoint of the equivalence ratio bin. 


\section{Table Captions}

Table 1. Operating conditions for the selected flames. Equivalence ratios $\phi_{i}$ and $\phi_{o}$ correspond to the inner and outer annular flows, respectively. The swirl number, $\mathrm{S}$, is defined as the ratio of the tangential to the axial momentum flow at the exit of the burner. The maximum value of $u$ '/ $S_{L}$ from three component velocity measurements [4] is listed. 


\begin{tabular}{|c|c|c|c|c|}
\hline Case & $\boldsymbol{\phi}_{\boldsymbol{i}}$ & $\boldsymbol{\phi}_{\boldsymbol{o}}$ & $\mathbf{S}$ & $\boldsymbol{u}^{\prime} / \boldsymbol{S}_{\boldsymbol{L}}$ at $z=\mathbf{3 0} \mathbf{~ m m}$ \\
\hline $\boldsymbol{S} w \boldsymbol{B} 1$ & 0.75 & 0.75 & 0.03 & 10.0 \\
\hline $\boldsymbol{S} w \boldsymbol{B} 3$ & 0.75 & 0.75 & 0.54 & 17.9 \\
\hline $\boldsymbol{S} w \boldsymbol{B} 11$ & 1.125 & 0.375 & 0.53 & 17.9 \\
\hline
\end{tabular}

Table 1. Operating conditions for the selected flames. Equivalence ratios $\phi_{i}$ and $\phi_{o}$ correspond to the inner and outer annular flows, respectively. The swirl number, $\mathrm{S}$, is defined as the ratio of the tangential to the axial momentum flow at the exit of the burner. The maximum value of $u$ ' $/ S_{L}$ from three component velocity measurements [4] is listed. 


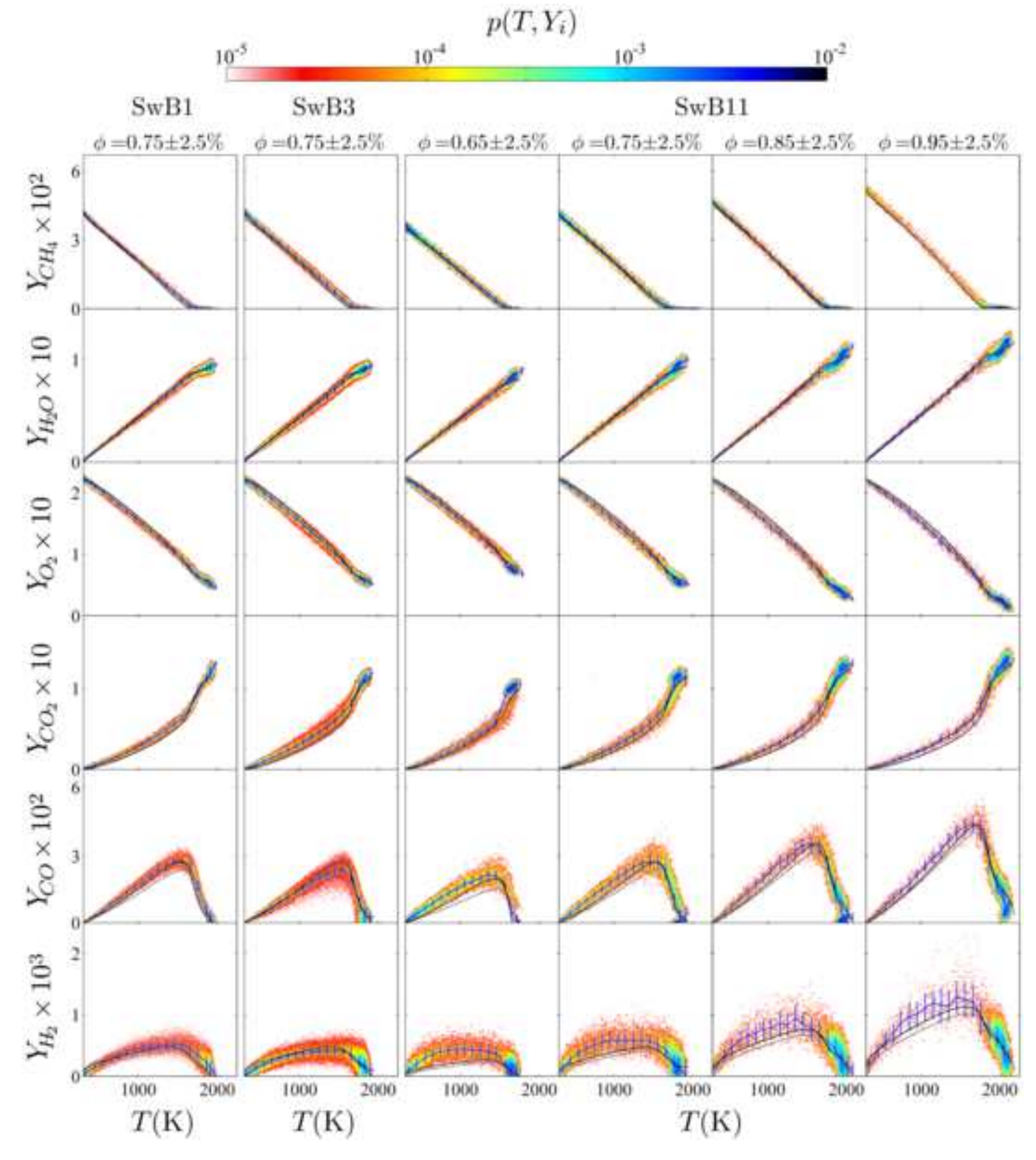

Figure

$p\left(T, Y_{i}\right)$

SwB1 SwB3

\section{SwB11}

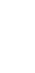

